\title{
The impact of the digital technological platforms on the institutional system of the higher education during the COVID 19 pandemic
}

\author{
Olga Fedotova ${ }^{1 *}$, Elena Platonova ${ }^{2}$, Oleg Igumnov ${ }^{2}$, Tong $\mathrm{Bu}^{2}$, and Tianhui Zhang ${ }^{2}$ \\ ${ }^{1}$ Don State Technical University, 344003, Rostov-on-Don, Russia \\ ${ }^{2}$ Moscow Pedagogical State University, 119571, Moscow, Russia
}

\begin{abstract}
The article is devoted to the assessment of the impact of the digital technological platforms on the higher education in the new conditions of the Covid-19 pandemic. The modern literature presents the various approaches to the analysis of the current situation in the higher education. The novelty of the authors ' approach is that the institutional system of the higher education is analyzed from the standpoint of the theories of new institutionalism. The authors considered the institutional system of the higher education as a four-level system. The article presents assessing the impact of the digital technological platforms on the first level of the institutional system of the higher education, which is represented by deeply rooted informal institutions (values, traditions, customs, unwritten norms and rules, and more). Assessing the impact of the digital technological platforms on other levels of the institutional system of the higher education requires the additional prospective research.
\end{abstract}

\section{Introduction}

The COVID 19 pandemic creates a fundamentally new situation in all spheres of society. Education had changed during the pandemic significantly, as other sectors of society. The OECD in collaboration with UNESCO, UNICEF and the World Bank has been monitoring the situation and collecting data on how many students are in pandemic conditions. In 2020, 1.5 billion students in 188 countries were involved in such situation [1].

The impact of the pandemic on society is so profound that many scientists support the thesis that after overcoming the pandemic, education will no longer have a situation "as usual." From the beginning of 2020 to the present, scientists have analyzed many issues as follows. First, changes in the methods of teaching university students based on the widespread use of remote digital technologies [2, 3, 4]. Secondly, the creation of favorable conditions during the pandemic for the uptake of educational material and the maintenance of a high level of quality of education, despite the remote communication between students and teachers $[5,6]$. Third, the needs to adapt the existing open-source learning digital platforms like the Moodle (Modular Object-Oriented Dynamic Learning Environment) based

\footnotetext{
*Corresponding author: fod1953@yandex.ru
} 
on the Internet to the possibility of a rapid shifting from full-time training to training under condition of the full or partial lockdowns $[7,8]$.

The analysis of published works shows a naturally increased interest of researchers to the didactic side of the new educational situation $[9,10]$. Some authors have discussed the psychological and pedagogical issues, proposing certain solutions for the socialization of students and teachers under the conditions of a long absence of direct communication with a team of fellow students or colleagues $[11,12]$.

In our opinion, with the collection of facts in the period of the pandemic, an integrated approach to the study of the deeper problem of the influence of the digital technological platforms on the institutional system of the higher education is relevant. At the same time, the institutional system of the higher education should be determined from the point of view of modern theories of institutionalism.

According to the views of representatives of institutionalism, the institutional system of the higher education is considered as a 4-tier system [13, 14]. Institutions of the first level transfer the prevailing values, traditions, customs, and rules to all members of the society. These are the informal institutions that regulate ingrained norms of behavior in society, including in the educational environment [15]. The second level of the institutional system of the of higher education is represented by formal institutions that reflect the specifics of national higher education systems established by national legislation and international standards adopted by national States. Each country has an extensive legal framework that regulates the field of higher education. In the Russian Federation, the legislative base in the field of higher education is based on the Constitution of the RF, Civil code of RF and the "Law on Education in the Russian Federation (the amendments entering into force on 01.09.2020). In the modern world, almost all national states are members of integration groups (for example, EU, CIS, etc.), or are members of international organizations (UN, OECD, SCO and others). Modern states voluntarily assume obligations to implement the international agreements in the field of higher education. For example, obligations arising from the accession of countries to the Bologna system. The third level includes institutions of governance, which directly manage state universities. The third level includes institutions of governance, which directly manage state universities, which are represented by two types of universities (an autonomous educational institution and budget educational institution of higher education). In Russia, institutions of governance include the Ministry of Science and Higher and the Education of the Russian Federation. At the same time, the latter one carries out the general management of 33 pedagogical universities. The Federal Education and Science Supervisory Service, which operates structurally in the system of the Government of the RF, monitors the implementation of the legislation by public and private universities [16]. The fourth level of institutional system of the higher education is composed of the University Charter, regulatory and administrative acts issued by universities, including in the execution of decisions of institutions of governance. This level includes the rules and norms prescribed in educational contracts with students and contracts with teachers, as well as university employees [17].

During the pandemic COVID 19, all levels of the institutional system of higher education have experienced certain changes, which are associated with the growing role of information technologies and digital technological platforms. The aim of the complex project of study is to identify how the teachers of higher education and the students from different areas of training and different courses of study at the university assess the impact of the digital technological platforms, in particular, using the Moodle platform, on the main elements of the institutional system of higher education. This paper presents the interim results concerning the assessment by university teachers of the impact of the digital technology platforms at the first level of the institutional system of higher education and shows the overall assessment by students of changes in the educational process associated with the 
shifting to digital technology platforms. Further continuation of the project will allow us to assess the complex impact of digital technology platforms at all other levels of the institutional system of higher education.

\section{Methodology and methods}

Various methods of study were used including literature analysis, survey, questionnaire, matching, graphic methods, comparison, review and interpretation. The empirical material was made up of the results of a survey of 25 teachers of the Institute of Social Studies and Humanities of MPSU that was conducted in February 2021. A survey of teachers and students has included the following stages: the development of research tools, conducting a survey, analysis of survey results and graphical representation for better visualization.

The important data source for analysis was the information on the analytical report named "Monitoring of trainees 'opinions on satisfaction issues quality of educational process". That report was made based on the results of a survey of 4,798 students and postgraduate students of various courses studying at MPSU during the period from December 2020 to mid-February 2021.

\section{Results and discussion}

The analysis of the content of the teachers ' answers to the questions allow us to give a detailed assessment of the impact of digital technological platforms (DTP) on the first level of institutional system of higher education (ISHE). First, a fundamental question was asked about whether the implementation of the DTP has an impact on the change of informal institutions in the field of higher education (values, traditions, customs, informal rules of behavior etc.). As it follows from Figure 1 the most of the teachers, who participated in the questionnaire acknowledged the facts of the change in informal institutions in the field of higher education.

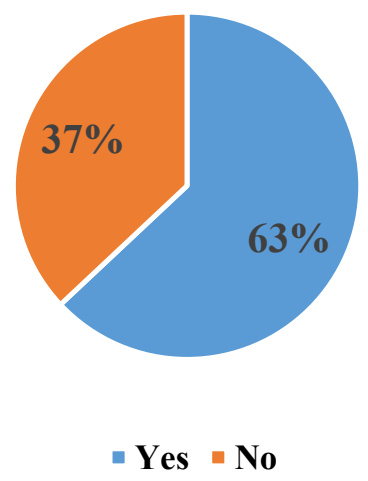

Fig. 1. Distribution of teacher's responses to the question: "During the transition of universities to digital technological platforms, whether informal institutions in the field of higher education have changed (values, traditions, customs, informal rules of behavior)?" ( $\% \%)$.

The results of the answers to the clarifying question about which of the values included in the values of the first level of ISHE have changed under the influence of the introduction of DTP are shown in Fig. 1. Moreover, each participant in the survey had to express an opinion on each item from the proposed sample of these values. Despite the fact that $37 \%$ of the interviewed teachers did not note institutional changes, all survey participants made a 
choice and assessed the level of institutional changes in the values of the first level of ISHE for each sample item.

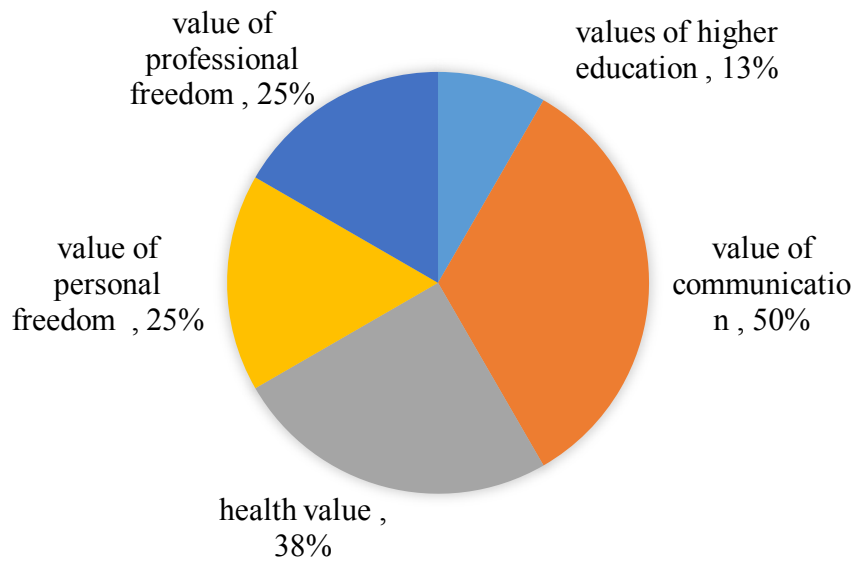

Fig. 2. Assessment of institutional changes in values of ISHE under the influence of DTP by type of values $(\% \%)$.

As can be seen from Fig. 2, the greatest changes relate to the values of communication and health. The assessment of changes of these values was $50 \%$ and $38 \%$, respectively, according to the survey participants.

For a deeper understanding of what changes in the value of communication occur under the influence of DTP, the answers of the respondents to the following clarifying questions are interesting. All participants denied the possibility of replacing teachers in the educational process of the DTP in the future. The result of the answers to the following question clarified the position of the survey participants regarding their attitude to the shifting to the DTP (see Fig. 3).

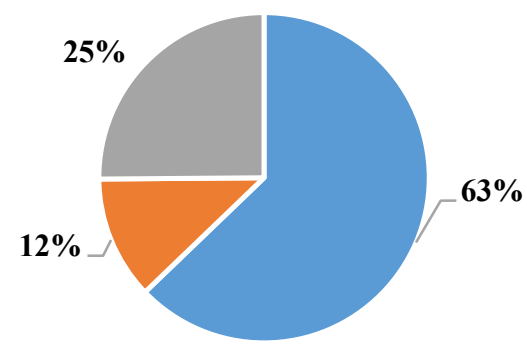

Negative $\quad$ Positive $\quad$ There are positive and negative points

Fig. 3. Distribution of teacher's responses to the question: "How do you assess the replacement of the centuries-old tradition of communication "student-teacher" with communication "student - computer screen (smartphone) - teacher?" ( \%\%).

The negative attitude of $63 \%$ of teachers causes the impossibility of a direct "alive" communication with students at lecture and seminars However, $25 \%$ of survey participants agree that a reasonable combination of traditional lectures and DPT is needed.

Shifting to DTP did not have a dramatic effect on the moral and psychological climate in the teaching team. The lack of communication with colleagues was felt by $37 \%$ of the surveyed 
teachers and $25 \%$ of teachers noted the deterioration of the moral and psychological climate in the teaching team (see Fig. 4).

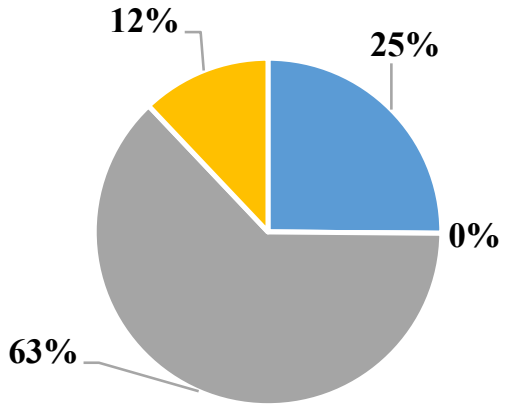

- Negative $=$ Positive $=$ Not affected $\|$ There are positive and negative points

Fig. 4. Distribution of teacher's responses to the question: "How did the transition to digital technologies affect the moral and psychological climate in the pedagogical team?" (\%).

A survey of students of MPGU showed that higher marks compared to 2019 were given in relation to the effectiveness of the use of electronic technologies and the organization of control of independent work through the Moodle system. This is explained by the imperative need for the urgent implementation of these technologies into the educational process in the spring of 2020. It can be argued that the COVID 19 pandemic has led to students ' awareness of the value of learning and the importance of making better use of Moodle's capabilities.

On the survey period, $21.9 \%$ of the surveyed students stated that they had no problems with learning during shifting to DTP. As it follows from the survey, 687 students $(25 \%)$ were satisfied with everything and $30.8 \%$ of the students did not want any changes. The fact that $10.6 \%$ of the surveyed students wanted to switch to full-time education, but only $6.7 \%$ voted for the extension of distance learning on the basis of the DTP testifies to the contradictory assessment of young people of the role of DTP in the educational process.

\section{Conclusion}

The analysis of the results of a survey of university teachers allowed showing the ambiguous assessments of the impact of DTP on the first level of ISHE during the COVID 19 pandemic. It should be taken into account that these assessments were influenced by the restrictions imposed by the state during the COVID 19 pandemic. Teachers of the higher school expressed a clearly negative attitude towards the prospect of eliminating lecture and seminar classes at universities, which provide an opportunity for teachers and students to communicate face to face. The main concern of university teachers is related to the possibility of the elimination of the alive direct communication between the students and lectors. University teachers consider communication as an unconditional value of society, which makes it possible to transfer not only information, but also experience and cultural code. Naturally, the results of the survey allow us to conclude that the cost of higher education is practically unchanged in any conditions, including in connection with the transition to DPT.

The contradictory responses of the students participating in the survey indicate that students are in the stage of adaptation after an unexpected transition to e:learning using Moodle. On the one hand, a little more than $10 \%$ of the surveyed students have expressed a 
desire to come back to full-time education, but, on the other hand, about $7 \%$ wanted to continue to study using DTP instead of classroom lessons with teachers. More detailed conclusions about the attitude of students to DTP as a technological tool, which one affects all aspects of the educational process can be made after the end of the COVID 19 pandemic.

Based on the interim results of our study, it can be argued with certainty that the completion of the current project requires the continuation of the research of the issue related the impact of DTP on other levels of ISHE.

\section{References}

1. The state of school education: One year into the COVID pandemic. https://oecdedutoday.com/oecd-education-webinars/

2. Ben Amram M., N. Davidovitch, Laplage Em Revista 7(2), 13-32 (2021)

3. P. Stanistreet, M. Elfert, D. Atchoarena, International Review of Education 66 (5-6), 627-633 (2020)

4. M. Grande-de-Prado, F.J. Garcia-Penalvo, A.C. Almuzara, V. Abella-Garcia, Campus Virtuales 10(1), 49-58 (2021)

5. O. Fedotova, E. Platonova, V. Latun, I. Filkevich, O. Igumnov, E3S Web Conference 210, (2020) doi.org/10.1051/e3sconf/202021022019

6. A.M. Muller, C. Goh, L. Lim, X.L. Gao, Education Sciences 11(1), (2021)

7. E. Perez-Lopez, A.V. Atochero, S.C. Rivero, Ried-Revista Iberoamericana De Educacion A Distancia 24 (1), 331-350 (2021)

8. I. Gomez-Hurtado, M.D. Garcia-Rodriguez, I. Gonzalez-Falcon, J.M. Llamas, Revista Internacional De Educacion Para La Justicia Social 9(3), 415-433 (2020)

9. A. Calikoglu, S. Gumus, Yuksekogretim Dergisi 10(3), 249-259 (2020)

10. O. Fedotova, P. Ermakov, S. Ponomareva, E. Platonova, Overcoming the psychological and cultural barriers of potential foreign students as a means of internationalizing university education, 13th international technology, education and development conference (INTED2019), 7688-7692 (2019) doi: 10.21125/inted.2019.1896

11. J.M. Del Castillo-Olivares, A. del Castillo-Olivares, Campus Virtuales 10(10), 89-101 (2021)

12. T. Agasisti, M. Soncin, Studies in Higher Education 46(1), 86-95 (2021)

13. O.E. Williamson, Journal of Economic Literature XXXVIII, 595-613 (2000)

14. F. Landini, Journal of Institutional Economics 9(3), 257-284 (2013)

15. E.J. Heikkila, Journal of Institutional Economics 7(1), 23-45 (2011)

16. E. Platonova, O. Fedotova, V. Latun, M. Musarskiy, O. Igumnov, State monitoring the effectiveness of Russian universities as the way of the improvement of the quality of higher education, EDULEARN18 proceedings 10105-10111 (2018) 